\title{
Investigation of Performance and Emission Characteristics of Diesel Blends with Pine Oil
}

\author{
J. Kishore Kumar ${ }^{1 \dagger}$, C. Sundar Raj², P. Sathishkumar ${ }^{3}$, P. Gopal ${ }^{3}$ and \\ A. Godwin Antony ${ }^{4}$ \\ ${ }^{1}$ Department of Mechanical Engineering, Sri Padmavathi College of Engineering, Kancheepuram, Tamil \\ Nadu, 602105, India \\ ${ }^{2}$ Department of Mechanical Engineering, A.V.C. College of Engineering, Mayiladuthurai, Nagapattinam, \\ Tamil Nadu, 609305, India \\ ${ }^{3}$ Department of Mechanical Engineering, University college of Engineering, BIT campus, Trichy, Tamil \\ Nadu, India, 620 001, India \\ ${ }^{4}$ Department of Mechanical Engineering, K. Ramakrishnan College of Technology, Trichy, Tamil Nadu \\ 621112, India
}

†Corresponding Author Email: kishorezeal80@gmail.com

(Received May 15, 2018; accepted July 18, 2018)

\begin{abstract}
It has been posted as a challenge for the researchers to identify an alternate fuel source for the petroleum fuels. This had become a major concern as the harmful pollutants are being produced in the exhaust of engines. The present works aims at the suitability study of esterified pine oil blended with diesel fuel as a replacement of diesel in an unmodified CI engine. The direct pine oil is a source obtained from agriculture. It has the innate characters like high viscosity, high calorific value and low cetane number values. It was found that esterified pine oil blended with diesel fuel could be successfully used with acceptable performance and better thermal efficiency. From the experimental investigation it is found that by blending pine oil with diesel, brake thermal efficiency can be increased up to $25 \%$, friction power can be reduced by $4 \mathrm{~kW}$. All the emission were observed to be low for the blended samples. The major contents like CO2 and NOx were decreased by $30 \%$. It is suggested to replace the diesel with pine oil blend for applications with low friction power and will thus help in achieving energy economy and rural economy development.
\end{abstract}

Keywords: Pine oil; Performance; Emission; Corrosion test.

\section{INTRODUCTION}

Vallinayagam et al. (2013a), conducted experiments with blends of Pine oil - diesel in a CI engine. Without any further modification to the engine, they have targeted to optimize the use of pine oil along with diesel. The blends are prepared due to the lower cetane number of the oil though the calorific value is at par with the diesel. It exhibited prolonged ignition delay and higher peak heat release rate, paving way for more NOX emission. Compared to fossil diesel, sample of 50D:50B (50\% diesel and 50\% pine oil) showed significant decrease in CO (carbon monoxide), HC (hydrocarbon) and smoke emission by $45.9 \%, 32.4 \%$ and $41.5 \%$, respectively, whereas the NOx (nitrogen oxides) emission was noted to be increased.

Vallinayagam et al (2013b), Investigated the effect of evaporation and engine characteristics of pine oil biofuel fumigated in the inlet manifold of a diesel engine. The work was based on fuels with less viscous and lower cetane number can be fumigated for successful operation in diesel engine. The evaporation characteristics of pine oil droplet were studied through suspended droplet experiment. The fumigation temperature was fixed at $150^{\circ} \mathrm{C}$ as effective evaporation of pine oil was achieved. The effect of vaporization of pine oil on engine characteristics was mapped by this study. The maximum percentage of diesel replaced was noticed to be $36 \%$ at $100 \%$ load and $60 \%$ at $20 \%$ load. Significantly, the engine performance such as BSFC and BTE was observed to be improved with the increase in proportion of pine oil injection.

Tamilselvan et al (2015), studied about the effect of pine oil on various performance, combustion and emission characteristics of a compression ignition engine. The fuel is renewable, biodegradable, 
oxygenated, sulfur free and reduces the adverse effects on climate change.

Prakash et al (2014) studied about the usage of emulsions obtained from Wood pyrolysis oil (WPO) and Jatropha methyl ester (JME) on combustion, performance and emission. It was revealed that up to $15 \%$ of WPO can be emulsified with the JME and used as a fuel in a DI diesel engine. The emulsion prepared from 81\% JME, $15 \%$ WPO with the help of a mixed surfactant $4 \%$ Z2JOE15 (on volume basis) was found to be better. The acidic nature was formed due to the addition of WPO. The acid quality of the emulsion was reduced by acid treatment. Srinivasan (2017) studied and analysed about the missile with grid fins and the effect on flow drag using ANSYS. Lakshmanan (2017) analysed the feasibility of using chicken fat oil blends of diesel in CI engine and revealed the results.

Karthikeyan et al (2007), described the use of turpentine oil in engine. The emission and performance characteristics of a D.I. diesel engine were studied under dual fuel (DF) mode. All other performance and emission characters were better than those of diesel, except volumetric efficiency. The pollutants like CO, UBHC were slightly higher than that of the diesel baseline (DBL). Smoke was reduced by $50 \%$ in DF mode. Deepak Agarwal et al (2007) studied about the performance and emissions characteristics of Jatropha oil in compression ignition engine. The $\mathrm{CO}_{2}$ can be reduced because of the agricultural origin. The operational problems of engine were observed due to the higher viscosity and low volatility. Parthasarathy et al (2014), experimented on, acetylene enriched air in DI diesel engine. Tamanu oil methyl ester (TME) and its blends were used in diesel engine. The NOx emission was increased greatly for the acetylene enriched air of $4 \mathrm{ppm}$ with TME 20 at full load condition. There was an increase of $11 \%$. CO emission.

\section{PINE OIL PREPARATION}

Harvest fresh pine tree needles from the pine tree. Do not use old pine tree needles that have already fallen to the ground, as these are more likely to mold and ruin your essential oil. Place the pine needles on a layer of paper towels to dry. Blot the needles with extra paper towels to remove all moisture from the surface. Place the pine needles into the mortar and pestle and gently bruise the leaves. If you are using a small pestle, bruise the needles in small batches until all of the needles are done. Pour the sweet almond oil into the largemouth glass jar. Add all of the pine needles to the jar. Cap the jar tightly and gently shake to coat the pine needles with the sweet almond oil. Store the jar in a warm room with an ambient temperature of at least 75 degrees Fahrenheit, out of direct sunlight. Shake the jar at least once a day for at least a week. After one week, store the jar in a dark location and allow the pine tree essential oil to age for 10 to 14 days. Do not shake the jar during this period. Remove the oil from the dark location, shake, and strain the oil through a piece of cheesecloth or finemesh cotton gauze. Squeeze the gauze to drain as much of the pine tree essential oil out as possible. The complete process is shown in figure 1.

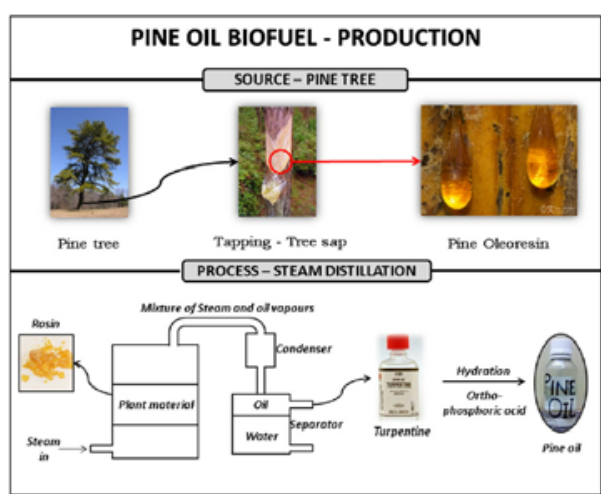

Fig. 1. Preparation of Pine oil from stock

\subsection{Blend Preparation}

Blending amounts of alternative fuel with conventional fuel is an important option for reducing petroleum consumption. Example of low level fuel blends include DP20 (80\% Diesel 20\% Pine oil), DP40 (60\% Diesel 40\% Pine oil), DP60 (60\% Diesel $40 \%$ Pine oil). Most pine oil users purchase DP20 or lower blends from their normal fuel distributors or from pine oil marketers. Regulated fleets that use pine oil blends of $20 \%$ (DP20) or higher qualify for pine oil fuel use credits under the Energy Policy Act of 1992.

Experimental investigation with pine oil-diesel blends in a diesel engine, it was perceived that 60D:40P (a mix of $40 \%$ pine oil with $60 \%$ diesel) was found to be the optimum blend because for blends beyond 60D:40P, the engine suffered some vibrations, especially at higher loads.

\subsection{Property Evaluation}

All the property values are estimated under the ASTM procedure and are tabulated below.

Table 1 Property value of the samples

\begin{tabular}{|c|c|c|c|c|c|}
\hline Sample & Density (g/ml) & Flash Point $\left({ }^{\circ} \mathrm{C}\right)$ & fire Point $\left({ }^{\circ} \mathrm{C}\right)$ & $\begin{array}{c}\text { Ash content } \\
(\mathrm{ml} / \mathrm{gm})\end{array}$ & $\begin{array}{c}\text { carbon residue } \\
(\mathrm{g} / \mathrm{ml})\end{array}$ \\
\hline Diesel & 822 & 90 & 95 & 0.1 & 0.15 \\
\hline Pine oil & 801 & 58 & 65 & 0.28 & 0.064 \\
\hline DP20 & 774.25 & 56 & 64 & 0.03 & 0.045 \\
\hline DP40 & 783.25 & 53 & 63 & 0.09 & 0.018 \\
\hline DP60 & 794.25 & 52 & 60 & 0.14 & 0.009 \\
\hline
\end{tabular}


Table 2 Corrosion test results of the sample

\begin{tabular}{|c|c|}
\hline Sample & copper strip corrosion test \\
\hline Diesel & Corrosive (4a) \\
\hline Pine oil & Slightly tarnish (1a) \\
\hline DP20 & moderate tarnish (2b) \\
\hline DP40 & moderate tarnish (2c) \\
\hline DP60 & dark tarnish (3c) \\
\hline
\end{tabular}

\section{PERFORMANCE TEST}

The test rig used in this study is shown in figure 2. It comprises of a four stroke diesel engine coupled to a rope brake for variable speed or electrical dynamometer. A water cooled brake drum along with spring balances, comprises rope brake. For electrical dynamometer water- rheostats is used as loading arrangement. With the help of various measurement provided, the test rig can determine BHP, IHP, mechanical \& thermal efficiencies, air fuel ratio, specific fuel consumption and heat balance sheet at various loads.

\subsection{Specific Fuel Consumption (SFC)}

Brake specific fuel consumption, fuel efficiency within a shaft reciprocating engine. The result for the variations in the brake specific fuel consumption (BSFC) is presented in the figure 3. For all the samples, the BSFC increase with increasing load. When compared with diesel, SFC in bio-diesel decrease about $30-40 \%$.

\subsection{Brake thermal efficiency}

Brake thermal efficiency is defined as brake power of a heat engine as a function of thermal input from the fuel. It is used to evaluate how well an engine converts the heat from fuel to mechanical energy. The variation of brake thermal efficiency with respect to brake power for pine oil - diesel blends and diesel fuel is shown in figure 4. It can be observed that the brake thermal efficiency increases along with increase in brake power. . When compared with diesel, Brake thermal efficiency is 40-45\% increased for the sample DP60. The figure 4 shows the BTE value of the study using various samples at different load conditions.

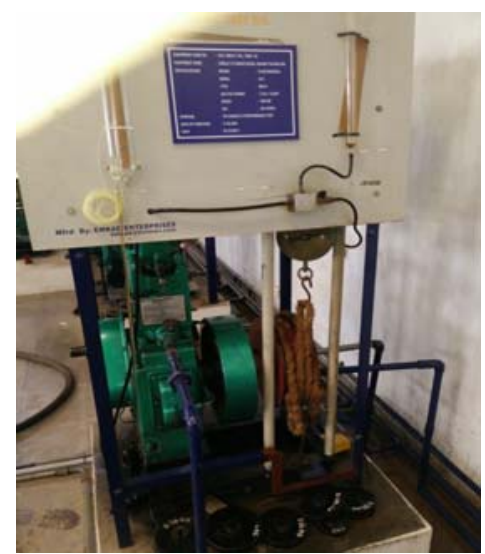

Fig. 2. Photographic view of test rig

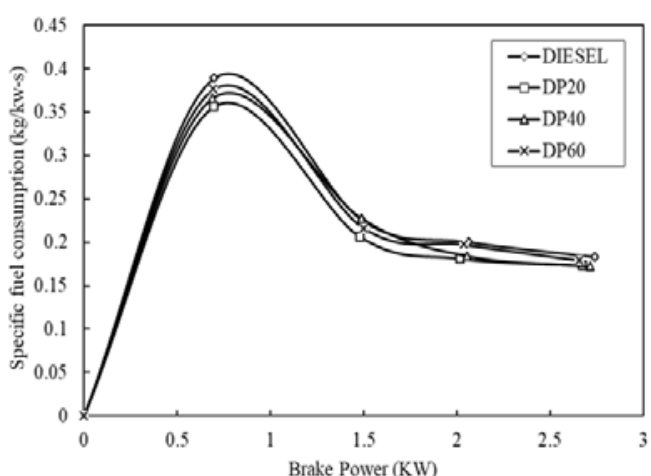

Fig. 3. Specific fuel consumption vs BP

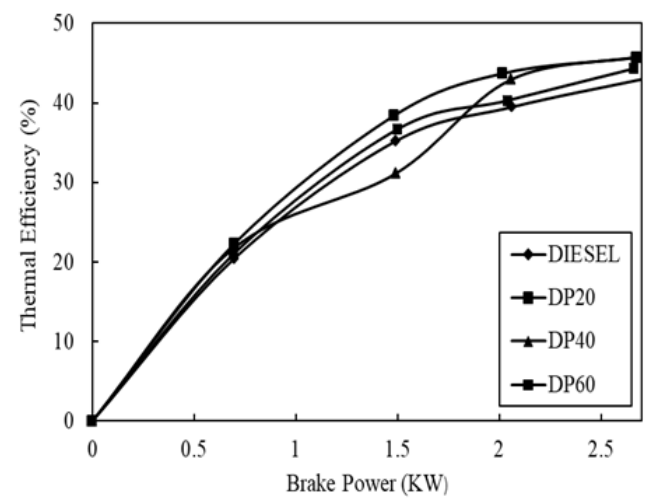

Fig. 4. Brake thermal efficiency vs BP

\section{EMISSION TEST}

\subsection{Carbon Monoxide Emission}

The CO emission is lower for the diesel fuel at the lower loads and increases during high loads as shown in figure 5 . The sample DP20 is showing relatively lower value of $\mathrm{CO}$ emission at all loads. The sudden rise may be due to the effect of knocking inside the combustion chamber that occurred while measuring. The sudden rise in temperature might have provided the necessary energy required for more amount of carbon dioxide to get dissociated into $\mathrm{CO}$ and oxygen ions.

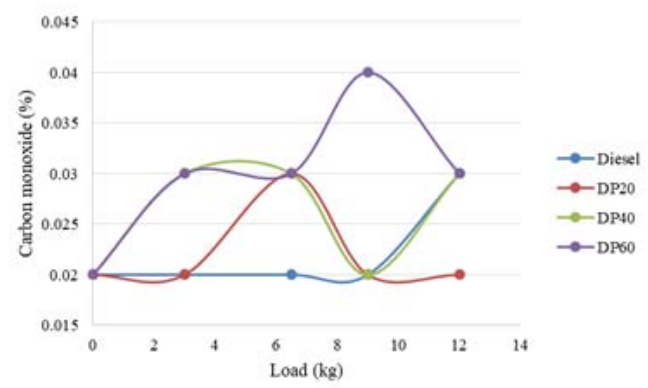

Fig. 5. Carbon monoxide vs load

\subsection{Hydrocarbon Emission}

The HC emission for the sample DP20 is showing a very much closer effect as the base diesel. The pine oil content added to the base fuel has increased the formation of saturated molecules of water and carbon dioxide. It is clear from the figure 6, the 
sample DP60 has the higher value of HC emission due to the presence of excessive pine oil content in the fuel. This excess amount has created an adverse effect of incomplete combustion due to the low flash and fire point values.

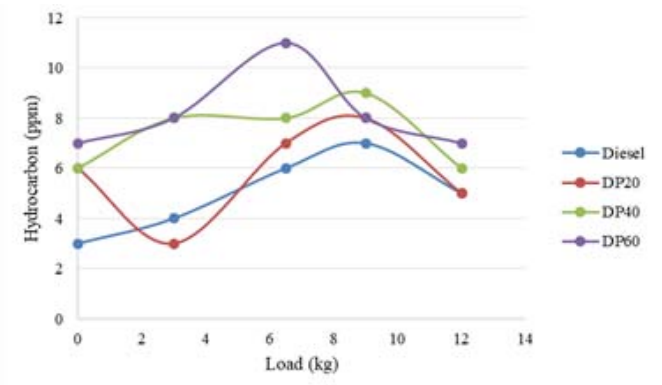

Fig. 6. Hydrocarbon emission vs load

\subsection{Carbon Dioxide Emission}

The $\mathrm{CO}_{2}$ emission for all the samples is shown in the figure 7. The sample DP20 shows once again a promising result with the lesser value of emission of $\mathrm{CO}_{2}$ than the plane diesel fuel. This is taking place because of the complete combustion occurred inside the chamber with the presence of pine oil. All the remaining samples show a very similar result in all the loads.

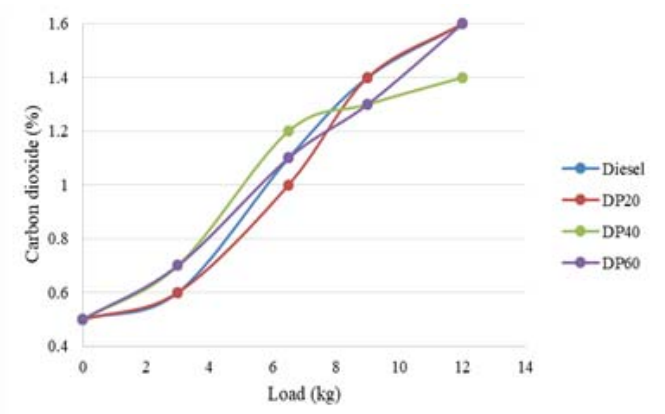

Fig. 7. Carbon dioxide emission vs load

\subsection{Nitrous Oxide Emission}

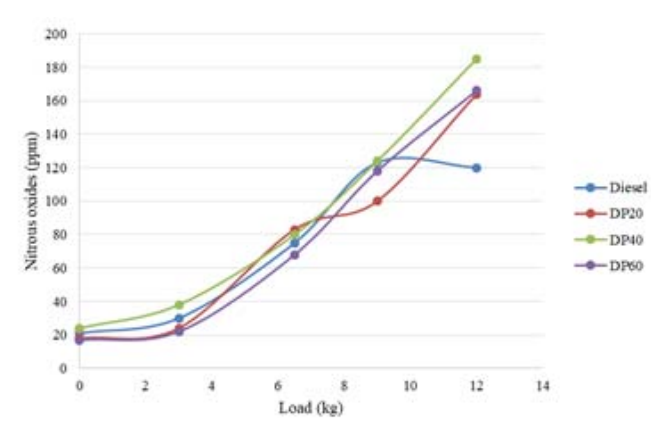

Fig. 8. Nitrous oxide vs load

The $\mathrm{NO}_{\mathrm{x}}$ emission is provided in the figure 8 for all the samples. Here the sample DP60 shows lesser $\mathrm{NO}_{\mathrm{x}}$ content because of the poor flash and fire point properties. The reduction in temperature of the combustion chamber is achieved by the excess heat being utilized to increase the temperature of the airfuel mixture. The samples with more pine oil content shows lesser $\mathrm{NO}_{\mathrm{x}}$ emission owing to that property. The sample DP20 shows lesser value than diesel at low load operations.

\section{CONCLUSION}

The present investigation aimed to analyze the usability of esterified pine oil blended with diesel fuel as a replacement of diesel in an unmodified CI engine.

- It was found that esterified pine oil blended with diesel fuel could be successfully used with acceptable performance and better thermal efficiency.

- The brake thermal efficiency can be increased up to $55-60 \%$.

- $\quad$ The friction power was finely reduced by 4 to 7 $\mathrm{kW}$ compared with sole diesel fuel.

- It is suggested to replace the diesel with pine oil blend for diesel engine application for getting better performance, low friction power.

- Emissions like $\mathrm{CO}_{2}, \mathrm{NO}_{\mathrm{x}}, \mathrm{CO}, \mathrm{HC}$ contents in pine oil blend is lower compared to that of diesel.

- The $\mathrm{CO}_{2}$ decreases about $20-28 \%$ and $\mathrm{NO}_{\mathrm{x}}$ emission decreased by $30-40 \%$, when compared to that of diesel.

\section{REFERENCES}

Deepak, A. and A. Avinash (2007). Performance and emissions characteristics of Jatropha oil (preheated and blends) in a direct injection compression ignition engine. Applied Thermal Engineering Applied Thermal Engineering 27, 2314-2323.

Karthikeyan, R. and N. V. Mahalakshmi (2007). Performance and emission characteristics of a turpentine-diesel dual fuel engine. Energy 32, 1202-1209.

Lakshmanan, P., P. Kaliyappan, M. Ranjithkumar, K. Aravinth, D. Vakkachan, C. Moorthy and S. Kumar, (2017) An Experimental Investigation to Study the Performance and Emission Characteristics of Chicken Fat Oil Fuelled DI Diesel Engine, Journal of Applied Fluid Mechanics 10 (Special Issue) 85-91.

Parthasarathy, M., J. R. Lalvani, Isaac, P. Muhilan, B. Dhinesh and K. Annamalai (2014). Experimental study of acetylene enriched air in di diesel engine powered by biodiesel- diesel blends. Journal of Chemical and Pharmaceutical Sciences 1.

Prakash R., R. K. Singh and S. Murugan, (2014) Experimental studies on combustion, performance and emission characteristics of diesel engine using different biodiesel bio oil emulsions. Journal- Energy Institute 88, 64-75.

Srinivasan, R., V. Vijayan and K. Sridhar, (2017) Computational Fluid Dynamic Analysis of Missile with Grid Fins Journal of Applied Fluid Mechanics10 (Special Issue) 33-39.

Tamilselvan, P. and N. Nallusamy 
J. Kishore Kumar et al. /JAFM, Vol. 11, Special Issue, pp. 63-67, 2018.

Performance, combustion and emission characteristics of a compression ignition engine operating on pine oil, Journal of biofuels 6 (5), $273-281$

Vallinayagam R., Vedharaj S., Yang W., Saravanan C., Lee P., Chua K. (2013a). Impact of ignition promoting additives on the characteristics of a diesel engine powered by pine oil-diesel blend.
Fuel;117:278-85.

Vallinayagam, R., Vedharaj, S., Yang, W., Lee, P., Chua, K., Chou, S. (2013b) Combustion performance and emission characteristics study of pine oil in a diesel engine. Energy 57, 34451. 